\title{
Anti-listeria effects of chitosan-coated nisin-silica liposome on Cheddar cheese
}

\author{
H. Y. Cui, ${ }^{*}$ J. Wu, ${ }^{*}$ C. Z. Li,† and L. Lin*1 \\ *School of Food and Biological Engineering, Jiangsu University, Zhenjiang 212013 P. R. China \\ †Hunan Academy of Forestry, Changsha 410007 P. R. China
}

\begin{abstract}
Listeria monocytogenes poses an increasing challenge to cheese production. To minimize the risk of bacterial contamination, a chitosan-coated nisin-silica liposome was engineered for the present study. We investigated the characteristics of nisin-silica liposomes and the anti-listeria effects of a chitosan-coated nisin-silica liposome on Cheddar cheese. The encapsulation efficiency of nisin in a liposome was sharply increased after it was adsorbed on a silica particle surface. Chitosan-coated nisin-silica liposomes displayed sustained antibacterial activity against L. monocytogenes, without affecting the sensory properties of the cheese. Chitosan-coated nisin-silica liposomes could be a promising active antimicrobial for cheese preservation.
\end{abstract}

Key words: nisin-silica liposome, chitosan coating, Listeria monocytogenes, Cheddar cheese

\section{INTRODUCTION}

Cheese is a popular dairy product due to its inherent high nutritional value, flavors, and textures. However, if cheese products are contaminated by pathogenic bacteria, bacteria multiply rapidly under eutrophic conditions. In the United States, 65 foodborne outbreaks linked to cheese were reported between 1993 and 2006 (Yoon et al., 2016). Listeria monocytogenes, a notable species of gram-positive bacteria, is frequently detected in cheese and can cause serious foodborne illness (Lin et al., 2016). It has a fatality rate of $30 \%$, possibly higher for people with low immunity and pregnant women (Chen et al., 2016). The application of natural antimicrobials (particularly bacteriocins) to cheese is essential for reducing L. monocytogenes contamination.

Nisin, produced by Lactococcus lactis ssp. lactis, is generally regarded as safe and has been approved as a natural food preservative by the World Health Orga-

Received June 26, 2016.

Accepted July 7, 2016.

${ }^{1}$ Corresponding author: linl@ujs.edu.cn nization (Zhu et al., 2015). Nisin has received special attention in the food industry due to its desired inhibitory effect on a large number of gram-positive bacteria, including L. monocytogenes and Staphylococcus aureus. Nisin can permeabilize membranes through a very efficient, lipid II-dependent, targeted pore-formation mechanism, leading to bacterial death (Breukink and Kruijff, 2006). Previous studies have reported that nisin can be added to various cheeses, such as Cheddar, Camembert, Manchego, Vidiago, and cottage cheeses, to protect against many foodborne pathogens (Aly et al., 2012). However, the negative interaction between bacteriocins such as nisin and food ingredients has been well demonstrated. Binding to food components such as fat and protein can reduce the free bacteriocins in foods (Aasen et al., 2003). As well, the degradation and inactivation of bacteriocins has been attributed to proteolytic activity (Devlieghere et al., 2004). Thus, the direct application of bacteriocins in food can reduce their effectiveness and influence the stability of the food (Malheiros et al., 2012). Encapsulating bacteriocins in nanoliposome systems could circumvent this problem, protecting the bacteriocins and enhancing their stability and bioactivity.

A liposome is an artificial vesicle composed of one or more lipid bilayers incorporating aqueous space. It has been exploited to envelop and release hydrophilic, hydrophobic and amphiphilic bioactive substances due its aqueous and lipid phases (Lin et al., 2015). In our previous studies, a nisin liposome was prepared using a thin film hydration method, but the encapsulation efficiency of the nisin in the liposome system was unsatisfactory. To enhance the encapsulation efficiency, silica, a food additive, has been used as a carrier of bacteriocins because of its high surface area, capacity for encapsulation, and biocompatibility (Bitar et al., 2012). However, aggregation and rupture of the membrane are likely to occur with liposomes, reducing the antibacterial activity of the encapsulated substance (Tan et al., 2013). An edible coating can be used as a carrier for the liposome, so that it is distributed evenly on the edible coating surface. 
Edible coatings obtained from biopolymers are being explored worldwide as a novel food packaging because they are simple, biodegradable, and eco-friendly (Sharma and Rao, 2015). In addition, an edible coating is a semipermeable barrier to gaseous exchange, moisture loss, and oxidative reactions (Pranoto et al., 2005). Among promising candidates, chitosan, a biocompatible polymer, has received widespread attention for its safety, good film-forming ability, excellent mechanical characteristics, and antibacterial performance (Sabaghi et al., 2015). Chitosan coating has been applied in the food industry to maintain food quality.

Based on the above analysis, the incorporation of a nisin-silica liposome into a chitosan edible coating has potential applications in food preservation. However, few studies are available on chitosan-coated nisin-silica liposomes. The main objective of the present study was to investigate the characteristics of nisin-silica liposomes and the sustaining antibacterial activities of chitosancoated nisin-silica liposomes against L. monocytogenes on Cheddar cheese, along with a sensory evaluation.

\section{MATERIALS AND METHODS}

\section{Materials and Culture}

Cheddar cheese (GRANG'OR Cheddar cheese; protein $25.6 \%$, fat $34.9 \%$, moisture content $37.1 \%$ ) was purchased from a local supermarket. Nisin (1,000 IU/ mg) was obtained from Luoyang Qihong Microbial Technology Co. Ltd. (Luoyang, China). Ammonia solution, absolute ethanol, tetraethylorthosilicate, chitosan, soy lecithin, cholesterol, trichloromethane, polyvinylpyrrolidone, and glycerol were purchased from Sinopharm Chemical Reagent Co., Ltd. (Shanghai, China). Listeria Chromogenic Medium was purchased from Huankai Microbial Technology Co. Ltd. (Guangzhou, China).

Listeria monocytogenes ATCC 19115, obtained from China General Microbiological Culture Collection Center (Beijing, China), was stored in liquid paraffin wax at $4^{\circ} \mathrm{C}$ and cultured with shaking at $37^{\circ} \mathrm{C}$ for $48 \mathrm{~h}$.

\section{Silica Preparation}

Silica was synthesized using a modified Stober method (Gangwar et al., 2013). Briefly, $4.0 \mathrm{~mL}$ of ammonia solution was mixed in $100 \mathrm{~mL}$ of ethanol solution $(80 \%$, $\mathrm{vol} / \mathrm{vol}$ ) with a magnetic stirrer for $40 \mathrm{~min}$ at $60^{\circ} \mathrm{C}$. Then, $4.0 \mathrm{~mL}$ of tetraethylorthosilicate was gradually added to the mixture, with continued stirring at $60^{\circ} \mathrm{C}$ for $90 \mathrm{~min}$. Next, the solution was evaporated in a vacuum oven at $40^{\circ} \mathrm{C}$. The silica powder obtained was washed 3 times with double-distilled water to remove unreacted species. The silica suspension was filtered through $0.1 \mu \mathrm{m}$ membranes to obtain uniform silica.

\section{Nisin and Nisin-Silica Encapsulation}

Nisin liposomes were prepared using a method reported by Malheiros et al. (2010) with minor modifications. Soy lecithin $(20 \mathrm{mg} / \mathrm{mL})$ and cholesterol $(4 \mathrm{mg} /$ $\mathrm{mL}$ ) were dissolved in trichloromethane. The organic solvent was evaporated using a rotary evaporator. The resulting thin film was hydrated in PBS $(0.03 M, \mathrm{pH}$ $7.2)$ containing nisin $(3,4,5$, and $6 \mathrm{mg} / \mathrm{mL})$ and polyvinylpyrrolidone $(1 \mathrm{mg} / \mathrm{mL})$. Then, the suspension was homogenized by using a cell ultrafine grinding instrument (Ymnl-1000Y; Nanjing Immanuel Instrument Equipment Co. Ltd., Nanjing, China) for 35 min. Finally, the nisin liposome solution was passed through $0.22-\mu \mathrm{m}$ membranes.

Nisin-silica liposomes were prepared for comparison using the same procedure, except for the addition of nisin-silica instead of nisin. Nisin $(3,4,5$, and $6 \mathrm{mg} /$ $\mathrm{mL}$ ) and silica $(2 \mathrm{mg} / \mathrm{mL})$ were mixed in PBS under stirring for $12 \mathrm{~h}$ to obtain a complex of nisin-silica.

\section{Preparation of Chitosan Coating Solutions}

To prepare the chitosan stock solution, $1 \%$ (wt/wt) chitosan was dispersed in acetic acid solution (1\%, vol/ vol) under magnetic stirring. Then, the stock solution was diluted with distilled water to obtain $0.1 \%$ (vol/ vol) chitosan solution. Glycerol $(0.5 \%$, vol $/ \mathrm{vol})$ was mixed into the chitosan solution $(0.1 \%, \mathrm{vol} / \mathrm{vol})$ as a plasticizer. For chitosan solutions containing liposomes, we added nisin liposomes (20\%, vol/vol) or nisin-silica liposomes $(20 \%, \mathrm{vol} / \mathrm{vol})$ under stirring (Jiménez et al., 2014). Finally, all chitosan coating solutions were filtered using a $0.22-\mu \mathrm{m}$ membrane.

\section{Characterization of Nisin Liposome and Nisin-Silica Liposome}

The particle size, polydispersity index (PDI), zeta potential, encapsulation efficiency (EE), and load content $(\mathbf{L C})$ of the nisin and nisin-silica liposomes were investigated. Quartz crystal microbalance was applied to verify that nisin had been encapsulated in the nisin and nisin-silica liposomes. Initially, particle size, PDI, and zeta potential of both liposomes were determined as described in previous studies (Cui et al., 2015, 2016). Then, EE and LC were measured using the bicinchoninic acid assay (Colas et al., 2007). Both liposomes were centrifuged at $9,659 \times g$ for $3 \mathrm{~h}$. The supernatants obtained were added to a France trace protein detec- 
tion kit (Nanjing Jiancheng Bioengineering Institute, Nanjing, China) to measure the concentration (conc.) of unencapsulated nisin. After that, EE and LC were calculated using the following equations:

$\mathrm{EE}(\%)=\frac{\text { overall nisin conc. }- \text { unencapsulated nisin conc. }}{\text { overall nisin conc. }}$ and

$$
\begin{aligned}
& \text { LC (\%wt/wt) } \\
& =\frac{\text { overall amt. of nisin }- \text { amt. of unencapsulated nisin }}{\text { amt. of lipid }},
\end{aligned}
$$

where amt. = amount. Quartz crystal microbalance was performed using QSX 301 gold sensors on a Q-Sense E4 instrument (Biolin Scientific Co., Ltd., Stockholm, Sweden) to analyze the slight difference in weights between the nisin liposomes $(5 \mathrm{mg} / \mathrm{mL})$ and the nisinsilica liposomes $(5 \mathrm{mg} / \mathrm{mL})$. For this experiment, 500 $\mu \mathrm{L}$ samples of each kind of liposome were needed. All experiments were conducted 3 times.

\section{Storage Stability of the Nisin-Silica Liposome}

The stability of the nisin-silica liposomes $(5 \mathrm{mg} / \mathrm{mL})$ was evaluated during storage. The nisin-silica liposome system was stored at $4^{\circ} \mathrm{C}$ and $25^{\circ} \mathrm{C}$ for $60 \mathrm{~d}$. The characteristics of the liposomes were determined over the storage period, including particle size, PDI, zeta potential, EE, and LC.

\section{Anti-listeria Activity of the Nisin-Silica Liposome in a Model Cheese Suspension}

Cheese and distilled water $(2: 8, \mathrm{wt} / \mathrm{wt})$ were blended into a slurry and sterilized. Cheese samples were inoculated with a $1 \%$ (vol/vol) of L. monocytogenes suspension (approximately $10^{5} \mathrm{cfu} / \mathrm{mL}$ ). Nisin $(0.05 \%)$, nisin liposomes $(20 \%$, vol/vol) or nisin-silica liposomes $(20 \%$, $\mathrm{vol} / \mathrm{vol}$ ) were each mixed into separate inoculated samples. Samples containing only L. monocytogenes were used as controls. The prepared samples were cultured separately at $25^{\circ} \mathrm{C}$ and $4^{\circ} \mathrm{C}$. Then, the numbers of $L$. monocytogenes were monitored for 7 and $14 \mathrm{~d}$ using the plate count method. All experiments were conducted 3 times.

\section{Anti-listeria Activity of the Chitosan-Coated Nisin-Silica Liposome in Model Cheese}

The plate colony-counting method was used to evaluate the anti-listeria activity of chitosan-coated nisinsilica liposomes. To prepare model cheese, the cheese suspension (20\%, wt/wt) was mixed into PYG agar medium and sterilized. Then, model cheese was formed using the plate-pouring method and cooled to room temperature. A L. monocytogenes suspension (approximately $10^{3} \mathrm{cfu} / \mathrm{mL}$ ) was dispersed well on the surface of the model cheese and maintained for $30 \mathrm{~min}$. Aliquots $(500 \mu \mathrm{L})$ of nisin liposome solution $(20 \%$, vol/ vol), nisin-silica liposome solution (20\%, vol/vol), pure chitosan coating solution, chitosan-coated nisin liposome solution, or chitosan-coated nisin-silica liposome solution were coated evenly onto the inoculated model cheese. Inoculated and uncoated model cheese samples were used as controls. Samples were cultured at $25^{\circ} \mathrm{C}$ and $4^{\circ} \mathrm{C}$. Residual bacteria were counted after culturing for $3 \mathrm{~d}$ and $5 \mathrm{~d}$.

\section{Anti-listeria Activity of the Chitosan-Coated Nisin-Silica Liposome on Cheese}

Fresh cheese samples $(30 \times 25 \times 10 \mathrm{~mm})$ were inoculated with $L$. monocytogenes suspension to obtain a target concentration of approximately $10^{3} \mathrm{cfu} / \mathrm{g}$. After $15 \mathrm{~min}$, the inoculated cheese samples were coated with pure chitosan coating solution, chitosan-coated nisin liposome solution, or chitosan-coated nisin-silica liposome solution (Figure 1). Inoculated and uncoated samples were used as controls. All samples were placed in aseptic plastic bags and stored at $25^{\circ} \mathrm{C}$ for $7 \mathrm{~d}$ or $4^{\circ} \mathrm{C}$ for $15 \mathrm{~d}$. Counts of L. monocytogenes were determined using a Listeria Chromogenic Medium. All experiments were conducted 3 times.

\section{Sensory Evaluation}

Fresh cheese $(30 \times 25 \times 10 \mathrm{~mm})$ without L. monocytogenes was coated with pure chitosan coating, chitosan-coated nisin liposomes, and chitosan-coated nisin-silica liposomes. Uncoated cheese samples were used as controls. Samples were placed in aseptic plastic bags and stored at $4^{\circ} \mathrm{C}$ for $15 \mathrm{~d}$. The sensory parameters (color, taste, texture, off-flavor, and overall acceptability) of cheese samples were assessed by 25 non-trained panelists (students and researchers) using a hedonic scale of 9 points, where $1=$ dislike extremely and $9=$ like extremely.

\section{Statistical Analysis}

All experiments were conducted 3 times. Results were analyzed using SPSS software (version 22.0; IBM Corp., Armonk, NY). Data are reported as means \pm SD. A one-way ANOVA and the Bonferroni statistical test were used to determine significant differences at a significance level of $P<0.05$. 


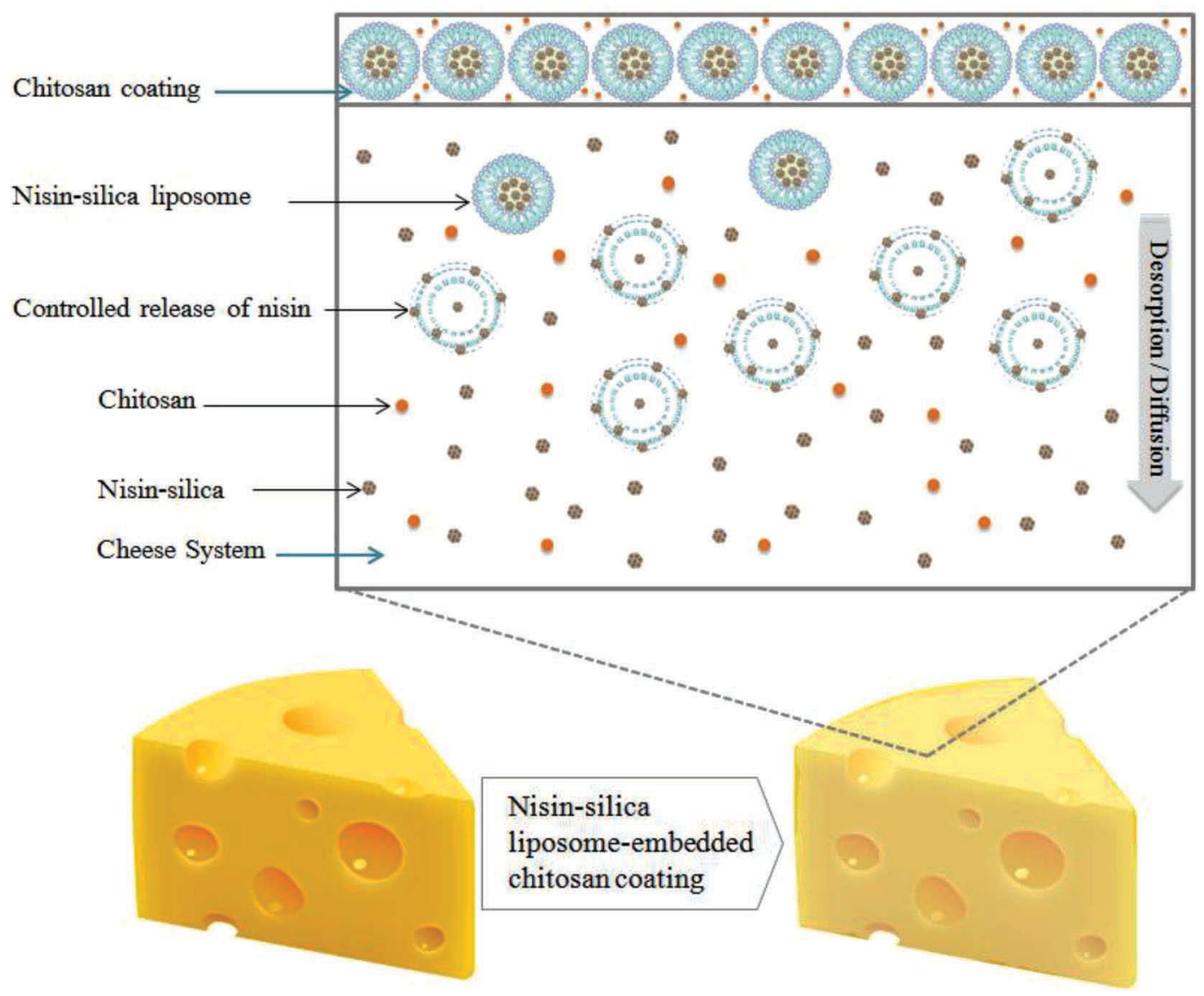

Figure 1. Release of chitosan-coated nisin-silica liposomes. Color version available online.

\section{RESULTS AND DISCUSSION}

\section{Characterization of Nisin Liposome and Nisin-Silica Liposome}

We analyzed the primary physicochemical properties of the nisin and nisin-silica liposomes. Particle size and PDI for the 2 kinds of liposome are displayed in Figure 2. Nisin liposomes had a size range of $102.6 \mathrm{~nm}$ to $134.3 \mathrm{~nm}$ for 3 to $6 \mathrm{mg} / \mathrm{mL}$ of nisin. The size of the nisin-silica liposomes ranged from $138.7 \mathrm{~nm}$ to 149.2 $\mathrm{nm}$. Compared with the nisin liposomes, incorporation of nisin-silica into the liposome system resulted in a slight increase in average size. The PDI is an index of the width of size distribution, and the PDI for the nisin and nisin-silica liposomes ranged from 0.245 to $0.293(<0.3)$, indicating uniformity (Tan et al., 2013). The zeta potential of the 2 types of liposomes in redistilled water ranged from -37.6 to $-44 \mathrm{mV}(<-30$ $\mathrm{mV}$; Figure 3), indicating that the 2 types of liposome suspensions were stable systems.
The EE and LC of the nisin and nisin-silica liposomes are shown in Figure 4. The EE value of the nisin liposome system ranged from 43.8 to $53.6 \%$, or low. The EE of the nisin-silica liposomes was higher, at 65.5 to $75.7 \%$. The EE of the nisin-silica liposomes reached its highest value at a nisin concentration of $5 \mathrm{mg} / \mathrm{mL}$ and declined at $6 \mathrm{mg} / \mathrm{mL}$. Compared with the nisin liposomes, the EE of nisin in the nisin-silica liposomes was sharply increased after it was adsorbed on the silica surface. The LC of the nisin and nisin-silica liposomes ranged from 6.57 to $21.36 \%$, indicating that nisin could be encapsulated into the liposomes within the studied concentrations.

Based on the above analysis, nisin-silica liposomes (5 $\mathrm{mg} / \mathrm{mL}$ ) were selected for further antibacterial testing due to their satisfactory size, EE, and LC.

Quartz crystal microbalance was used to evaluate the slight difference in weights between the nisin liposomes $(5 \mathrm{mg} / \mathrm{mL})$ and the nisin-silica liposomes $(5 \mathrm{mg} / \mathrm{mL})$. The shift in frequency $(\Delta \mathrm{F})$ showed an attractive interaction between the liposome vesicles and the gold sub- 


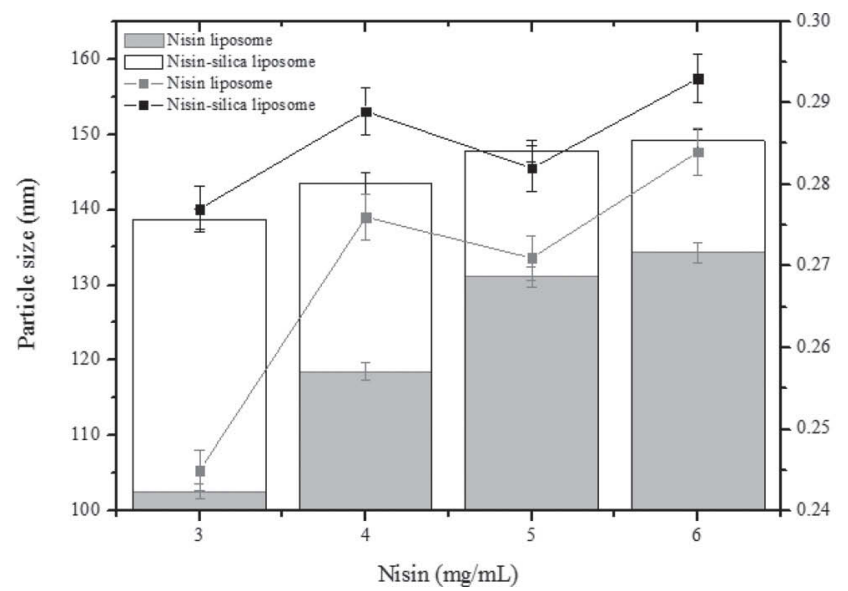

Figure 2. The particle size and polydispersity index (PDI) of nisin liposomes and nisin-silica liposomes with different concentrations of nisin encapsulation. Error bars for values of particle size represent SD $=1.34$. Error bars for values of polydispersity index represent $\mathrm{SD}=$ 0.0027 .

strate (Figure 5). Compared with empty liposomes, the mass of the nisin and nisin-silica liposomes increased markedly, and the nisin-silica liposomes had the largest mass. The results verified that nisin and nisin-silica were encapsulated in the liposome systems.

\section{Storage Stability of Nisin-Silica Liposome}

We evaluated the stability of the nisin-silica liposomes $\left(5 \mathrm{mg} / \mathrm{mL}\right.$ ) stored at $25^{\circ} \mathrm{C}$ (Table 1$)$ and $4^{\circ} \mathrm{C}$ (Table 2 ).

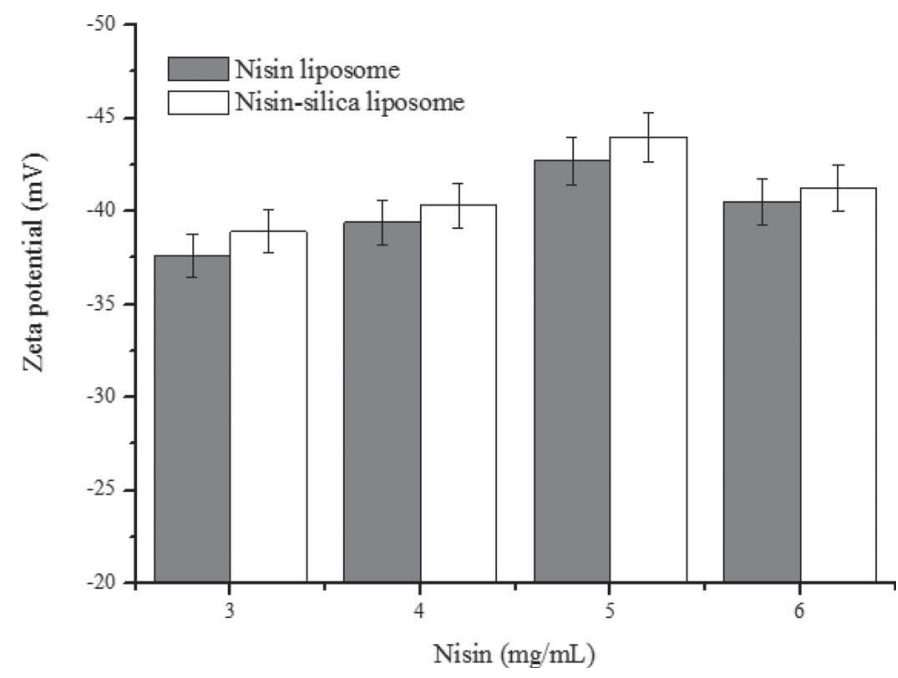

Figure 3. The zeta potential of nisin liposomes and nisin-silica liposomes with different concentrations of nisin encapsulation. Error bars represent $\mathrm{SD}=1.28$.

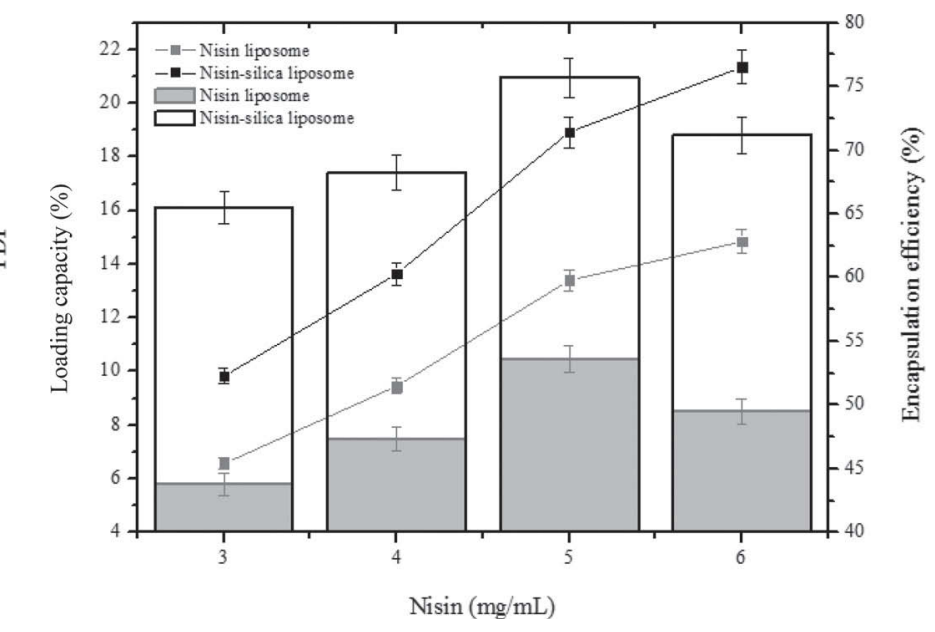

Figure 4. The loading capacity and encapsulation efficiency of nisin liposomes and nisin-silica liposomes with different concentrations of nisin encapsulation. Error bars for values of loading capacity represent $\mathrm{SD}=0.45$. Error bars for values of encapsulation efficiency represent $\mathrm{SD}=1.31$.

During storage at $25^{\circ} \mathrm{C}$, the particle size of the nisinsilica liposomes ranged from $145.3 \pm 1.39 \mathrm{~nm}$ to 142.8 $\pm 1.75 \mathrm{~nm}$, but we observed no significant changes over the storage period. The PDI of the liposomes was below 0.3 , and the zeta potential was less than $-30 \mathrm{mV}$ over time. The EE and LC of the nisin-silica liposomes underwent no significant changes during storage. We observed similar results for the nisin-silica liposomes stored at $4^{\circ} \mathrm{C}$. Nisin-silica had practically no leakage

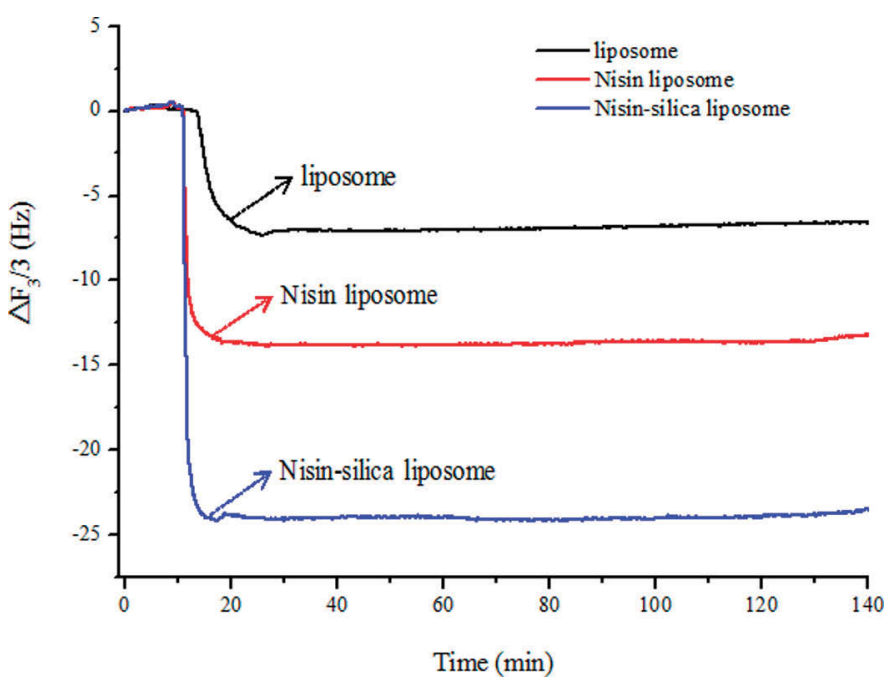

Figure 5. The shift in frequency $(\Delta \mathrm{F})$ of empty liposomes, nisin liposomes, and nisin-silica liposomes. Color version available online. 
Table 1. Changes in variables (means $\pm \mathrm{SD}$ ) for nisin-silica liposomes over the storage period at $25^{\circ} \mathrm{C}^{1}$

\begin{tabular}{lccccc}
\hline & \multicolumn{5}{c}{ Variable } \\
\cline { 2 - 6 } $\begin{array}{l}\text { Storage } \\
\text { period }(\mathrm{d})\end{array}$ & $\begin{array}{c}\text { Particle } \\
\text { size }(\mathrm{nm})\end{array}$ & $\begin{array}{c}\text { Polydispersity } \\
\text { index }\end{array}$ & $\begin{array}{c}\text { Zeta } \\
\text { potential }(\mathrm{mV})\end{array}$ & $\begin{array}{c}\text { Encapsulation } \\
\text { efficiency }(\%)\end{array}$ & $\begin{array}{c}\text { Load } \\
\text { content }(\%)\end{array}$ \\
\hline 10 & $144.9 \pm 1.51$ & $0.269 \pm 0.018$ & $-42.9 \pm 1.23$ & $72.8 \pm 0.83$ & $18.2 \pm 0.61$ \\
20 & $145.3 \pm 1.39$ & $0.248 \pm 0.026$ & $-41.6 \pm 1.89$ & $73.1 \pm 0.55$ & $18.3 \pm 0.58$ \\
30 & $143.6 \pm 1.42$ & $0.257 \pm 0.035$ & $-43.0 \pm 1.57$ & $72.0 \pm 0.67$ & $18.0 \pm 0.86$ \\
60 & $142.8 \pm 1.75$ & $0.231 \pm 0.023$ & $-42.4 \pm 1.61$ & $71.6 \pm 0.78$ & $17.9 \pm 0.77$ \\
\hline
\end{tabular}

${ }^{1}$ Values within the same column for each variable over the storage period are not significantly different $(P>$ $0.05)$.

Table 2. Changes in variables (means $\pm \mathrm{SD}$ ) for nisin-silica liposomes over the storage period at $4^{\circ} \mathrm{C}^{1}$

\begin{tabular}{|c|c|c|c|c|c|}
\hline \multirow[b]{2}{*}{$\begin{array}{l}\text { Storage } \\
\text { period }(\mathrm{d})\end{array}$} & \multicolumn{5}{|c|}{ Variable } \\
\hline & $\begin{array}{l}\text { Particle } \\
\text { size (nm) }\end{array}$ & $\begin{array}{l}\text { Polydispersity } \\
\text { index }\end{array}$ & $\begin{array}{c}\text { Zeta } \\
\text { potential }(\mathrm{mV})\end{array}$ & $\begin{array}{l}\text { Encapsulation } \\
\text { efficiency (\%) }\end{array}$ & $\begin{array}{c}\text { Load } \\
\text { content }(\%)\end{array}$ \\
\hline 10 & $146.4 \pm 1.68$ & $0.276 \pm 0.014$ & $-43.1 \pm 1.63$ & $73.5 \pm 0.79$ & $18.4 \pm 0.37$ \\
\hline 20 & $145.7 \pm 1.23$ & $0.264 \pm 0.025$ & $-44.9 \pm 2.54$ & $72.8 \pm 0.95$ & $18.2 \pm 0.61$ \\
\hline 30 & $143.1 \pm 1.45$ & $0.258 \pm 0.019$ & $-42.7 \pm 2.19$ & $71.9 \pm 0.64$ & $17.9 \pm 0.53$ \\
\hline 60 & $144.3 \pm 1.36$ & $0.261 \pm 0.032$ & $-41.8 \pm 3.45$ & $71.1 \pm 0.83$ & $17.8 \pm 0.75$ \\
\hline
\end{tabular}

${ }^{1}$ Values within the same column for each variable over the storage period are not significantly different $(P>$ $0.05)$.

Table 3. Antibacterial activity (log cfu/g; means $\pm \mathrm{SD}$ ) of nisin-silica liposomes against Listeria monocytogenes in the model cheese suspension stored at $25^{\circ} \mathrm{C}$

\begin{tabular}{|c|c|c|c|c|c|c|c|c|}
\hline \multirow[b]{2}{*}{ Treatment } & \multicolumn{8}{|c|}{ Incubation period (d) } \\
\hline & 0 & 1 & 2 & 3 & 4 & 5 & 6 & 7 \\
\hline Nisin & $3.58 \pm 0.41$ & $3.32 \pm 0.26^{\mathrm{a}}$ & $4.85 \pm 0.34^{\mathrm{a}}$ & $6.11 \pm 0.39^{\mathrm{b}}$ & $6.83 \pm 0.37^{\mathrm{b}}$ & $7.41 \pm 0.52^{\mathrm{c}}$ & $7.56 \pm 0.48^{\mathrm{c}}$ & $7.65 \pm 0.40^{c}$ \\
\hline Nisin liposome & $3.61 \pm 0.38$ & $4.39 \pm 0.35^{\mathrm{b}}$ & $5.59 \pm 0.27^{\mathrm{b}}$ & $6.43 \pm 0.51^{\mathrm{b}}$ & $6.76 \pm 0.44^{\mathrm{b}}$ & $6.88 \pm 0.58^{\mathrm{b}}$ & $6.95 \pm 0.31^{\mathrm{b}}$ & $6.99 \pm 0.42^{\mathrm{b}}$ \\
\hline Nisin-silica liposome & $3.59 \pm 0.40$ & $4.08 \pm 0.23^{\mathrm{b}}$ & $4.78 \pm 0.41^{\mathrm{a}}$ & $5.18 \pm 0.36^{\mathrm{a}}$ & $5.34 \pm 0.49^{\mathrm{a}}$ & $5.40 \pm 0.57^{\mathrm{a}}$ & $5.45 \pm 0.51^{\mathrm{a}}$ & $5.48 \pm 0.43^{\mathrm{a}}$ \\
\hline
\end{tabular}

${ }^{\mathrm{a}-\mathrm{d}}$ Distinct letters within the same column indicate significant differences at the same incubation period $(P<0.05)$.

Table 4. Antibacterial activity (log cfu/g; means $\pm \mathrm{SD}$ ) of nisin-silica liposomes against Listeria monocytogenes in the model cheese suspension stored at $4^{\circ} \mathrm{C}$

\begin{tabular}{|c|c|c|c|c|c|c|c|c|}
\hline \multirow[b]{2}{*}{ Treatment } & \multicolumn{8}{|c|}{ Incubation period (d) } \\
\hline & 0 & 2 & 4 & 6 & 8 & 10 & 12 & 14 \\
\hline$\overline{\text { Control }}$ & $3.34 \pm 0.30$ & $3.81 \pm 0.34^{\mathrm{c}}$ & $4.51 \pm 0.25^{\mathrm{b}}$ & $5.38 \pm 0.39^{c}$ & $6.18 \pm 0.41^{\mathrm{d}}$ & $6.54 \pm 0.37^{\mathrm{d}}$ & $6.77 \pm 0.48^{\mathrm{d}}$ & $6.88 \pm 0.32$ \\
\hline Nisin & $3.30 \pm 0.27$ & $2.90 \pm 0.13^{\mathrm{a}}$ & $3.99 \pm 0.19^{\mathrm{a}}$ & $5.04 \pm 0.27^{\mathrm{c}}$ & $5.76 \pm 0.35^{\mathrm{c}}$ & $6.10 \pm 0.41^{\mathrm{c}}$ & $6.32 \pm 0.34^{\mathrm{c}}$ & $6.48 \pm 0.40^{\circ}$ \\
\hline Nisin liposome & $3.33 \pm 0.31$ & $3.28 \pm 0.24^{\mathrm{b}}$ & $3.83 \pm 0.31^{\mathrm{a}}$ & $4.52 \pm 0.25^{\mathrm{b}}$ & $4.94 \pm 0.33^{\mathrm{b}}$ & $5.41 \pm 0.42^{\mathrm{b}}$ & $5.66 \pm 0.28^{\mathrm{b}}$ & $5.83 \pm 0.35^{\mathrm{b}}$ \\
\hline Nisin-silica liposome & $3.31 \pm 0.29$ & $3.11 \pm 0.23^{\mathrm{b}}$ & $3.69 \pm 0.27^{\mathrm{a}}$ & $3.96 \pm 0.34^{\mathrm{a}}$ & $4.26 \pm 0.30^{\mathrm{a}}$ & $4.36 \pm 0.43^{\mathrm{a}}$ & $4.43 \pm 0.34^{\mathrm{a}}$ & $4.48 \pm 0.22^{\mathrm{a}}$ \\
\hline
\end{tabular}

${ }^{\mathrm{a}-\mathrm{d}}$ Distinct letters within the same column indicate significant differences at the same incubation period $(P<0.05)$.

Table 5. Antibacterial activity (log cfu/g; means $\pm \mathrm{SD}$ ) of chitosan-coated nisin-silica liposomes against Listeria monocytogenes on cheese stored at $25^{\circ} \mathrm{C}$

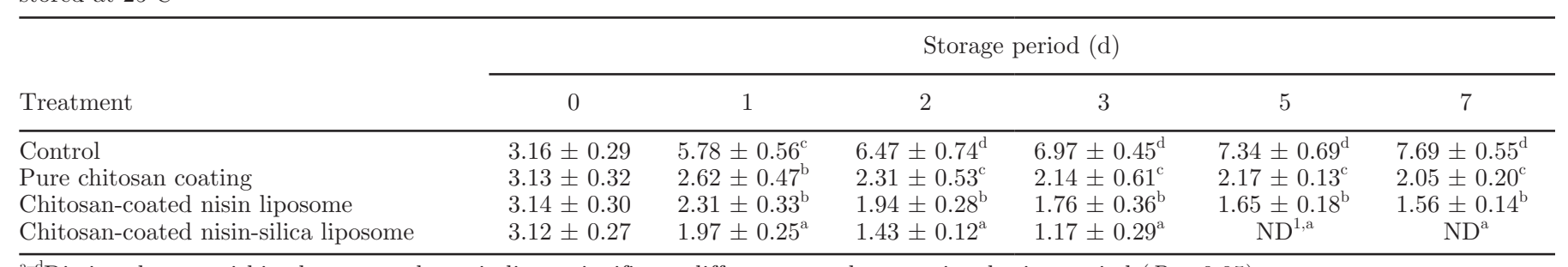

${ }^{\mathrm{a}-\mathrm{d}}$ Distinct letters within the same column indicate significant differences at the same incubation period $(P<0.05)$.

${ }^{1} \mathrm{ND}=$ nondetectable; the value is below the limit of detection $(1.0 \log \mathrm{cfu} / \mathrm{g})$. 


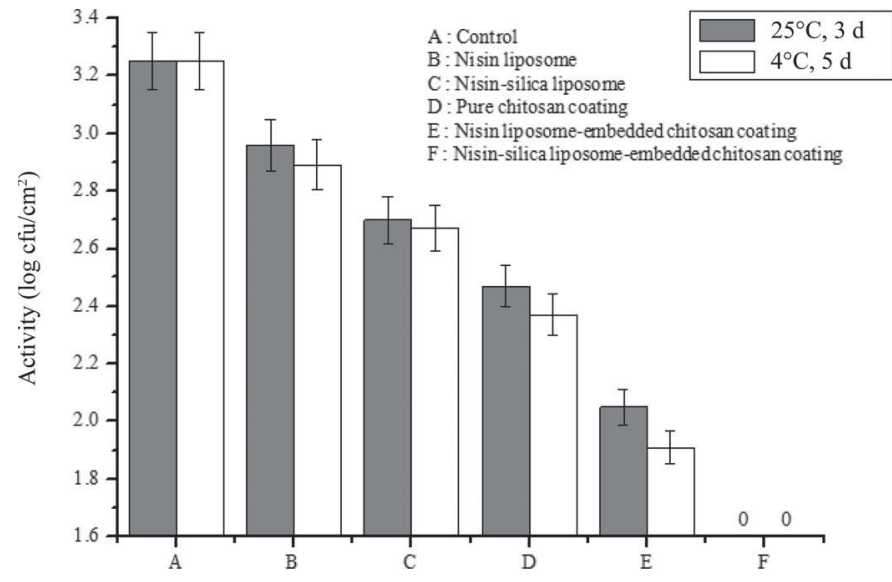

Figure 6. The antibacterial activity of chitosan-coated nisin-silica liposomes against Listeria monocytogenes in model cheese at $25^{\circ} \mathrm{C}$ and $4^{\circ} \mathrm{C}$. Error bars represent $\mathrm{SD}=0.089$.

from the liposomes, indicating that the nisin-silica liposomes had good stability during storage.

\section{Anti-listeria Activity of the Nisin-Silica Liposome in a Model Cheese Suspension}

We evaluated the antibiotic activity of the nisinsilica liposomes against L. monocytogenes in a model cheese suspension at $25^{\circ} \mathrm{C}$ (Table 3) and $4^{\circ} \mathrm{C}$ (Table 4). During incubation at $25^{\circ} \mathrm{C}$, the numbers of viable bacteria gradually increased. Compared with controls, L. monocytogenes in nisin samples increased slowly up to $1 \mathrm{~d}$, but afterward we observed gradual growth of viable bacteria because of nisin deactivation and degradation (Imran et al., 2012). After 3 d, the numbers of L. monocytogenes in nisin liposome samples were increased by $2.82 \log _{10}$ steps, and those in nisin-silica liposome samples were increased by $1.59 \log _{10}$ steps. We observed similar results for the cheese suspension incubated at $4^{\circ} \mathrm{C}$. These findings indicated that the nisinsilica liposomes displayed obviously antibiotic activity against L. monocytogenes in a cheese suspension due to its relatively high EE.

\section{Anti-listeria Activity of the Chitosan-Coated Nisin-Silica Liposome in Model Cheese}

Figure 6 shows the antibiotic activity of the chitosancoated nisin-silica liposomes against L. monocytogenes in model cheese stored at $25^{\circ} \mathrm{C}$ and $4^{\circ} \mathrm{C}$. Compared with controls $\left(3.25 \log \mathrm{cfu} / \mathrm{cm}^{2}\right)$ incubated at $25^{\circ} \mathrm{C}$, the numbers of $L$. monocytogenes in the model cheese coated with the nisin liposomes and the nisin-silica liposomes were 2.96 and $2.70 \log \mathrm{cfu} / \mathrm{cm}^{2}$, respectively. However, the numbers of $L$. monocytogenes on the model cheese coated with pure chitosan coating, chitosan-coated nisin liposomes, and chitosan-coated nisin-silica liposomes were $2.47 \log \mathrm{cfu} / \mathrm{cm}^{2}, 2.05 \log \mathrm{cfu} / \mathrm{cm}^{2}$, and below the limit of detection. We observed similar results for model cheese incubated at $4^{\circ} \mathrm{C}$. These findings indicated that chitosan-coated nisin-silica liposomes had better control of L. monocytogenes than the other groups.

\section{Anti-listeria Activity of Nisin-Silica Liposome- Embedded Chitosan Coating on Cheese}

Results for the antibacterial activity of the chitosancoated nisin-silica liposomes against L. monocytogenes on cheese stored at $25^{\circ} \mathrm{C}$ and $4^{\circ} \mathrm{C}$ are shown in Table 5 and Table 6, respectively. Generally, L. monocytogenes on cheese grew faster at $25^{\circ} \mathrm{C}$ than at $4^{\circ} \mathrm{C}$. The numbers of L. monocytogenes in the controls at $25^{\circ} \mathrm{C}$ increased rapidly during storage and achieved $7.69 \log \mathrm{cfu} / \mathrm{g}$ at 7 d. The numbers of $L$. monocytogenes on cheese treated with pure chitosan coating and chitosan-coated nisin liposomes were reduced by $0.96 \mathrm{log} \mathrm{cfu} / \mathrm{g}$ and $1.49 \mathrm{log}$ $\mathrm{cfu} / \mathrm{g}$ at $5 \mathrm{~d}$, respectively. However, L. monocytogenes growth was distinctly inhibited by the chitosan-coated nisin-silica liposomes at $5 \mathrm{~d}$. Similarly, the numbers of $L$. monocytogenes in the control samples at $4^{\circ} \mathrm{C}$ increased to $6.65 \log \mathrm{cfu} / \mathrm{g}$ at $15 \mathrm{~d}$. The growth of $L$. monocytogenes was inhibited by the pure chitosan coating and the chitosan-coated nisin liposomes: numbers at $6 \mathrm{~d}$ were reduced by $0.84 \mathrm{log} \mathrm{cfu} / \mathrm{g}$ and $1.16 \mathrm{log}$ $\mathrm{cfu} / \mathrm{g}$, respectively. However, the numbers of $L$. monocytogenes on cheese treated with the chitosan-coated

Table 6. Antibacterial activity (log $\mathrm{cfu} / \mathrm{g}$; means $\pm \mathrm{SD}$ ) of chitosan-coated nisin-silica liposomes against Listeria monocytogenes on cheese stored at $4^{\circ} \mathrm{C}$

\begin{tabular}{|c|c|c|c|c|c|c|}
\hline Treatment & \multicolumn{6}{|c|}{ Storage period $(\mathrm{d})$} \\
\hline Control & $3.11 \pm 0.28$ & $3.49 \pm 0.34^{\mathrm{c}}$ & $4.26 \pm 0.41^{\mathrm{d}}$ & $5.67 \pm 0.49^{\mathrm{d}}$ & $6.32 \pm 0.33^{\mathrm{c}}$ & $6.65 \pm 0.52^{\mathrm{c}}$ \\
\hline Chitosan-coated nisin liposome & $3.08 \pm 0.29$ & $2.27 \pm 0.18^{\mathrm{b}}$ & $1.92 \pm 0.23^{\mathrm{b}}$ & $1.69 \pm 0.15^{\mathrm{b}}$ & $1.57 \pm 0.22^{\mathrm{b}}$ & $1.49 \pm 0.17^{\mathrm{b}}$ \\
\hline Chitosan-coated nisin-silica liposome & $3.06 \pm 0.27$ & $1.56 \pm 0.14^{\mathrm{a}}$ & $\mathrm{ND}^{1, \mathrm{a}}$ & $\mathrm{ND}^{\mathrm{a}}$ & $\mathrm{ND}^{\mathrm{a}}$ & $\mathrm{ND}^{\mathrm{a}}$ \\
\hline
\end{tabular}

\footnotetext{
${ }^{\mathrm{a}-\mathrm{d}}$ Distinct letters within the same column indicate significant difference at same incubation period $(P<0.05)$.

${ }^{1} \mathrm{ND}=$ nondetectable; the value is below the limit of detection $(1.0 \log \mathrm{cfu} / \mathrm{g})$.
} 
Table 7. Sensory evaluation of cheese samples coated with chitosan-coated nisin-silica liposome and before storage (fresh) or stored at $4^{\circ} \mathrm{C}$ for $15 \mathrm{~d}$

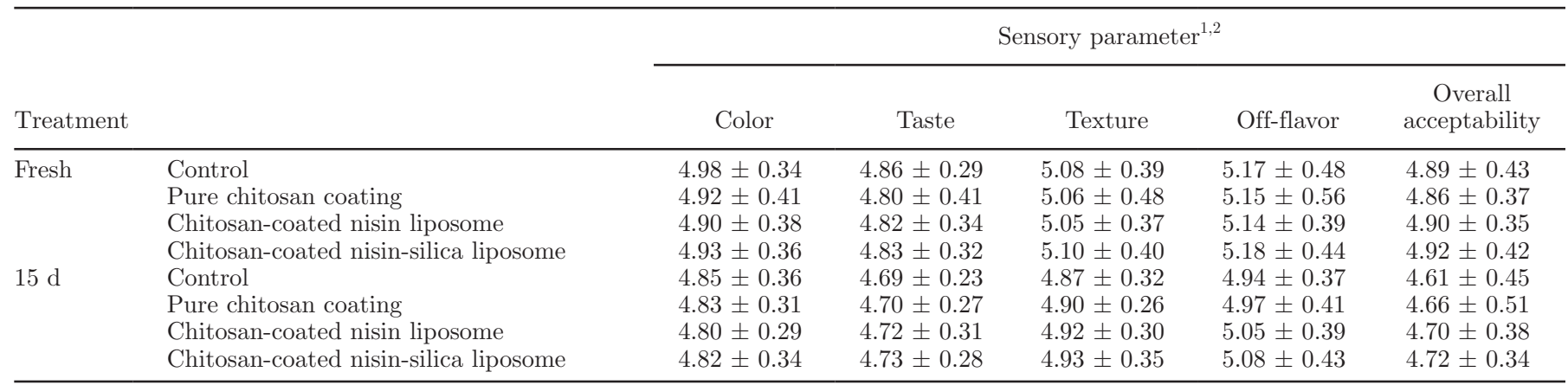

${ }^{1}$ Values within the same column for each variable over the storage period are not significantly different $(P>0.05)$.

${ }^{2}$ Data are the means $( \pm \mathrm{SD})$ of a 9 -point hedonic scale: $1=$ dislike extremely; $2=$ dislike very much; $3=$ dislike somewhat; $4=$ dislike; $5=$ neither like nor dislike; $6=$ like; $7=$ like somewhat; $8=$ like very much; $9=$ like extremely.

nisin-silica liposomes were below the limit of detection at $6 \mathrm{~d}$, indicating that the chitosan-coated nisin-silica liposomes showed significant antibiotic activity against L. monocytogenes. It could be a promising active package for prolonging the shelf stability of cheese.

\section{Sensory Evaluation}

Table 7 shows the findings for the sensory evaluation of cheese samples treated with the chitosan-coated nisin-silica liposomes and stored at $4^{\circ} \mathrm{C}$. The sensory quality of the samples declined somewhat at the end of storage. However, we observed no significant differences in sensory score among the cheese samples at various storage times. The results indicated that chitosancoated nisin-silica liposomes could maintain the sensory properties of cheese.

\section{CONCLUSIONS}

This study investigated the physicochemical properties of nisin-silica liposomes and the antibiotic activity of chitosan-coated nisin-silica liposomes against $L$. monocytogenes in cheese models, along with a sensory evaluation of the cheese. The results showed that the $\mathrm{EE}$ of nisin in nisin-silica liposomes sharply increased after it was adsorbed on the silica surface. Moreover, chitosan-coated nisin-silica liposomes showed the desired antibacterial activity against L. monocytogenes without altering the sensory properties of cheese samples. Chitosan-coated nisin-silica liposomes could be a promising active package for food preservation.

\section{ACKNOWLEDGMENTS}

The authors acknowledge the financial support provided by the National Natural Science Foundation of China (Beijing, China; 31301573), the Natural Science Foundation of Jiangsu Province (Nanjing, China; BK20130493), and the Jiangsu University research foundation (Zhenjiang, China; 11JDG050).

\section{REFERENCES}

Aasen, I. M., S. Markussen, T. Møretrø, T. Katla, L. Axelsson, and K. Naterstad. 2003. Interactions of the bacteriocins sakacin P and nisin with food constituents. Int. J. Food Microbiol. 87:35-43.

Aly, S., J. Floury, M. Piot, S. Lortal, and S. Jeanson. 2012. The efficacy of nisin can drastically vary when produced in situ in model cheeses. Food Microbiol. 32:185-190.

Bitar, A., N. M. Ahmad, H. Fessi, and A. Elaissari. 2012. Silica-based nanoparticles for biomedical applications. Drug Discov. Today 17:1147-1154.

Breukink, E., and B. D. Kruijff. 2006. Lipid II as a target for antibiotics. Nat. Rev. Drug Discov. 5:321-332.

Chen, X. R., X. W. Zhang, R. Z. Meng, Z. W. Zhao, Z. H. Liu, X. C. Zhao, C. Shi, and N. Guo. 2016. Efficacy of a combination of nisin and $p$-anisaldehyde against Listeria monocytogenes. Food Contr. 66:100-106.

Colas, J. C., W. Shi, V. S. N. M. Rao, A. Omri, M. R. Mozafari, and H. Singh. 2007. Microscopical investigations of nisin-loaded nanoliposomes prepared by Mozafari method and their bacterial targeting. Micron 38:841-847.

Cui, H. Y., J. Wu, and L. Lin. 2016. Inhibitory effect of liposomeentrapped lemongrass oil on the growth of Listeria monocytogenes in cheese. J. Dairy Sci. 99:6097-6104.

Cui, H. Y., C. T. Zhao, and L. Lin. 2015. The specific antibacterial activity of liposome-encapsulated clove oil and its application in tofu. Food Contr. 56:128-134.

Devlieghere, F., L. Vermeiren, and J. Debevere. 2004. New preservation technologies: Possibilities and limitations. Int. Dairy J. $14: 273-285$.

Gangwar, R. K., G. B. Tomar, V. A. Dhumale, S. Zinjarde, R. B. Sharma, and S. Datar. 2013. Curcumin conjugated silica nanoparticles for improving bioavailability and its anticancer applications. J. Agric. Food Chem. 61:9632-9637.

Imran, M., A. M. Revol-Junelles, N. René, M. Jamshidian, M. J. Akhtar, E. Arab-Tehrany, M. Jachout, and S. Desobry. 2012. Microstructure and physico-chemical evaluation of nano-emulsionbased antimicrobial peptides embedded in bioactive packaging films. Food Hydrocoll. 29:407-419.

Jiménez, A., L. Sánchez-González, S. Desobry, A. Chiralt, and E. A. Tehrany. 2014. Influence of nanoliposomes incorporation on prop- 
erties of film forming dispersions and films based on corn starch and sodium caseinate. Food Hydrocoll. 35:159-169.

Lin, L., H. Y. Cui, H. Zhou, X. J. Zhang, L. Liu, C. Bortolini, M. L. Chen, and M. D. Dong. 2015. Nanoliposomes containing eucalyptus citriodora antibiotics for specific antimicrobial activity. Chem. Commun. (Camb.) 51:2653-2655.

Lin, L., X. J. Zhang, C. T. Zhao, and H. Y. Cui. 2016. Liposome containing nutmeg oil as targeted preservative against Listeria monocytogenes in dumplings. RSC Advances 6:978-986.

Malheiros, P. S., Y. M. S. Micheletto, N. P. D. Silveira, and A. Brandelli. 2010. Development and characterization of phosphatidylcholine nanovesicles containing the antimicrobial peptide nisin. Food Res. Int. 43:1198-1203.

Malheiros, P. D. S., V. Sant'Anna, M. D. S. Barbosa, A. Brandelli, and B. D. G. D. M. Franco. 2012. Effect of liposome-encapsulated nisin and bacteriocin-like substance P34 on Listeria monocytogenes growth in Minas Frescal cheese. Int. J. Food Microbiol. 156:272-277.

Pranoto, Y., S. K. Rakshit, and V. M. Salokhe. 2005. Enhancing antimicrobial activity of chitosan films by incorporating garlic oil, potassium sorbate and nisin. Food Sci. Technol.38:859-865.
Sabaghi, M., Y. Maghsoudlou, M. Khomeiri, and A. M. Ziaiifar. 2015. Active edible coating from chitosan incorporating green tea extract as an antioxidant and antifungal on fresh walnut kernel. Postharvest Biol. Technol. 110:224-228.

Sharma, S., and T. V. R. Rao. 2015. Xanthan gum based edible coating enriched with cinnamic acid prevents browning and extends the shelf-life of fresh-cut pears. Food Sci. Technol.62:791-800.

Tan, C., S. Q. Xia, J. Xue, J. H. Xie, B. Feng, and X. M. Zhang. 2013. Liposomes as vehicles for lutein: Preparation, stability, liposomal membrane dynamics, and structure. J. Agric. Food Chem. 61:8175-8184.

Yoon, Y., S. Lee, and K. H. Choi. 2016. Microbial benefits and risks of raw milk cheese. Food Contr. 63:201-215.

Zhu, X. M., H. Wu, J. Yang, J. Tong, J. Y. Yi, Z. H. Hu, J. Hu, T. Wang, and L. H. Fan. 2015. Antibacterial activity of chitosan grafting nisin: Preparation and characterization. React. Funct. Polym. 91-92:71-76. 